\author{
Hannelore Ehrenreich - Thomas Rinn · Hanns J. Kunert \\ Manfred R. Moeller · Wolfgang Poser \\ Lothar Schilling • Gerd Gigerenzer • Margret R. Hoehe
}

\title{
Specific attentional dysfunction in adults following early start of cannabis use
}

Received: 15 June 1998/Final version: 30 September 1998

\begin{abstract}
Rationale and objective: The present study tested the hypothesis that chronic interference by cannabis with endogenous cannabinoid systems during peripubertal development causes specific and persistent brain alterations in humans. As an index of cannabinoid action, visual scanning, along with other attentional functions, was chosen. Visual scanning undergoes a major maturation process around age 12-15 years and, in addition, the visual system is known to react specifically and sensitively to cannabinoids. Methods: From 250 individuals consuming cannabis regularly, 99 healthy pure cannabis users were selected. They were free of any other past or present drug abuse, or history of neuropsychiatric disease. After an interview, physical examination, analysis of routine laboratory parameters, plasma/urine analyses for drugs, and MMPI testing, users and respective controls were subjected to a computer-assisted attention test battery comprising visual scanning, alertness, divided attention, flexibility, and working memory. Results: Of the potential predictors of test performance within the user group,
\end{abstract}

H. Ehrenreich · T. Rinn · H.J. Kunert · W. Poser

Departments of Psychiatry and Neurology, Georg August

University, Göttingen, Germany

H. Ehrenreich $(\bowtie) \cdot$ T. Rinn · H.J. Kunert · W. Poser

Max Planck Institute for Experimental Medicine,

Hermann-Rein-Strasse 3, D-37075 Göttingen, Germany

e-mail: ehrenreich@exmax1.mpiem.gwdg.de,

Fax: +49-551-3899670

M.R. Moeller

Institute of Legal Medicine, State University of Saarland, Homburg, Germany

L. Schilling

Department of Neurosurgery, University Hospital,

Mannheim, Germany

G. Gigerenzer

Max-Planck-Institute for Human Development, Berlin, Germany

M.R. Hoehe

Max-Delbrück-Center for Molecular Medicine, Berlin, Germany including present age, age of onset of cannabis use, degree of acute intoxication ( $\mathrm{THC}+\mathrm{THCOH}$ plasma levels), and cumulative toxicity (estimated total life dose), an early age of onset turned out to be the only predictor, predicting impaired reaction times exclusively in visual scanning. Early-onset users (onset before age $16 ; n=48$ ) showed a significant impairment in reaction times in this function, whereas late-onset users (onset after age 16;n=51) did not differ from controls $(n=49)$. Conclusions: These data suggest that beginning cannabis use during early adolescence may lead to enduring effects on specific attentional functions in adulthood. Apparently, vulnerable periods during brain development exist that are subject to persistent alterations by interfering exogenous cannabinoids.

Key words Cannabinoids - Neuropsychology ·

Visual scanning $\cdot$ Attentional function .

Development

\section{Introduction}

For both its recreative and medicinal properties, cannabis has been used and abused for thousands of years. Today, it represents the illicit drug most widely consumed, especially by young people. Consumption has been increasing in the western world during the past years, growing into a problem of substantial proportions. Regular intake of cannabis by youngsters has been associated with disruptive effects on family life, education, the pursuit of intellectual careers, and job motivation. In fact, the "amotivational syndrome hypothesis" claims that regular marijuana use in young people may contribute to the development of passive, inward-turning, amotivational personality characteristics (McGlothlin and West 1968). Ongoing debates on legalization of cannabinoids have intensified 
discussions on potential persistent effects of cannabinoids on brain functions, which have not been clearly demonstrated in humans thus far (Pope et al. 1995). The characteristic effects of $\Delta 9$-tetrahydrocannabinol ( $\triangle 9-\mathrm{THC})$, the major psychoactive constituent of cannabis, on cognition and behavior have mainly been viewed as effects of a transient intoxication with rapid onset and a return to "normal" within a few hours to days (Hollister 1986; Pope et al. 1995). Recent studies, however, have questioned such a fast return to normal (Block 1996; Fletcher et al. 1996; Pope and YurgelunTodd 1996; Solowij et al. 1995).

Cannabinoids exert their cognitive and behavioral effects through specific interaction with brain cannabinoid receptors. A high density of these binding sites in cortical and subcortical brain structures known to be involved in the complex organization of cognitive and emotional networks (Mesulam 1981, 1990; Mirsky 1987; Posner and Petersen 1990; Halgren and Marinkovic 1995; Zihl and Hebel 1997) has been shown by autoradiography, RNA isolation and in situ hybridization. Not only do cannabinoid receptors belong to the most abundantly expressed neurotransmitter receptors in the brain, but interestingly, their distribution in specific brain areas is also unique and highly conserved in mammalian species (Herkenham et al. 1990; Matsuda et al. 1990; Mailleux et al. 1992; Thomas et al. 1992; Westlake et al. 1994). Receptor densities in these areas vary during developmental stages, specifically during puberty, and reflect differential maturation of cannabinoid-related systems. Most importantly, receptors undergo downregulation in response to chronic THC stimulation (McLaughlin and Abood 1993; Oviedo et al. 1993; Rodrígez de Fonseca et al. 1993, 1994), and chronic exposure of immature rats to cannabinoid administration has been shown to result in irreversible discrete effects on behavior and brain morphology (Stiglick and Kalant 1985; Landfield et al. 1988). This suggests a particular vulnerability to chronic cannabis administration during certain phases of development. To date, no studies have addressed such potential vulnerability to cannabis use in humans.

This study is concerned with the effects of early onset of cannabis use. Early onset is not infrequent. For instance, the US National Household Survey on Drug Abuse estimates the proportion of adolescents aged 12-17 years using marijuana as $7.1 \%$ in 1996 (US Department of Health and Human Services 1996). Does early onset of cannabis use impair attentional functions in adult life? In the present study, we look for evidence concerning the hypothesis of a specific and persistent impairment of visual scanning. This hypothesis is based on two kinds of observations: (1) in a previous study assessing the development of attentional functions in 253 healthy children, adolescents and adults, we found visual scanning to have the most pronounced acceleration of the speed of information processing in mid-puberty (age 12-15 years) among various functions that are known to be affected by cannabis use (Kunert et al. 1996); (2) a specific receptivity of the visual system to cannabinoids is reflected by data on marijuana intoxicated subjects showing an impaired speed of visual information processing (Braff et al. 1981). If one puts these two observations - a pronounced acceleration of visual scanning around age $12-15$, and a specific receptivity of the visual system to cannabinoids - together, then the hypothesis emerges that early onset of cannabis use may lead to enduring effects on visual scanning in adult life.

\section{Materials and methods}

The study protocol has been approved by the Committee for Medical Ethics (Georg-August-University of Göttingen, Germany). Subjects participated after having given their written informed consent. A substantial number of carefully selected healthy young regular cannabis consumers were recruited by advertising in the local newspapers in Göttingen, Germany, a university town with approximately 30000 students. The minimum requirement for "regular use" was a once-per-week consumption of cannabis for at least half a year. Strict criteria were defined to collect a homogeneous sample of 99 pure cannabis users, predominantly accustomed to intake via inhalation. As controls, 49 healthy young individuals, comparable regarding age, sex, and educational status, without any past or present drug (including cannabis) consumption were used. Both groups consisted predominantly of students, thus forming a fairly homogeneous sample concerning sociodemographic status and intelligence. The groups did not differ with respect to the estimated premorbid intelligence level (Wilson et al. 1978). All subjects were within $15 \%$ of their ideal body weight. They were free of any past or present neurologic or psychiatric disease, or head injury. Individuals with previous or present abuse of other drugs (with the exception of nicotine or caffeine) were rejected. Alcohol consumption was accepted only in an occasional and modest manner $(\leq 3$ beers per week). At the time of testing, subjects had to be free of any alcohol. In order objectively to confirm the inclusion criteria and to control the validity of the subjects' verbal reports, each individual underwent a complete physical examination. In addition, samples were taken from each test subject for (a) blood analysis of routine laboratory parameters, (b) extensive urine screening (using immunological routine methods) for drugs of abuse (benzodiazepines, barbiturates, amphetamines, ephedrines, morphine and related opioids, methadone, cocaine, alcohol), (c) determination of blood concentrations of $\triangle 9 \mathrm{THC}$ and its major metabolites, THCOH and $\mathrm{THCCOOH}$, by gas chromatography/mass spectrometry (Moeller et al. 1992) and (d) measurement of total THC metabolites in urine by fluorescent polarization immunoassay (FPIA) (Moeller et al. 1992). Moreover, subjects underwent a semistructured psychiatric interview and a psychopathometric test (Minnesota multiphasic personality inventory; short version, MMPI-S) to exclude individuals with depression or other psychopathological conditions potentially affecting test results. Of 250 cannabis consumers screened, 110 were tested and of those, 11 had to be excluded retrospectively (high depression score: $n=8$; alcohol in the urine sample: $n=3$ ). Only 99 users were included in the final evaluation. All tests were carried out in random order, and the time of day of each testing was documented to control for a possible influence on performance. The total life dose of cannabis was extrapolated, based on the past and present consumption habits of individual users. (Subjects had to estimate the average number of days of consumption per week separately for each half year over the total years of use.) 
Attention testing

To evaluate specifically a spectrum of attentional functions, the computer-assisted test battery recently developed by Zimmermann and Fimm (1993) was administered. This test battery integrates experimental and clinical evidence collected, relating defined functional and morphological brain damage to specific attentional dysfunctions (Mesulam 1981, 1990; Mirsky 1987; Posner and Petersen 1990; Halgren and Marinkovic 1995; Zihl and Hebel 1997). The five subtests used and described in the following were selected because they evaluate the functions of brain areas known to express cannabinoid receptors (Herkenham et al. 1990; Matsuda et al. 1990; Mailleux et al. 1992; Thomas et al. 1992; Westlake et al. 1994).

In visual scanning, a total of 100 serially appearing square matrices, each consisting of $5 \times 5$ small squares all open to one particular side, have to be read. The subject is asked to respond to the presence or absence ("critical versus non-critical stimulus") of a Ushaped square in the matrix by pushing one of two buttons accordingly. This test addresses complex overlapping cortical and subcortical networks. It reflects the ability visually to scan and identify critical stimuli, integrating the generation of eye movement (involving subcortical structures like the superior colliculus, thalamus and striatum). Alertness measures the reaction time to a crossshaped stimulus presented on the monitor screen without a preceding acoustic signal ("tonic alertness") and with one, representing functions related to reticulo-thalamo-frontal pathways. The median reaction times in both conditions and their difference divided by the median reaction time of the total test are then calculated ("phasic alertness," representing the ability to enhance the level of attention, in expectation of a high-priority stimulus). The experiment is carried out via ABBA design (A: without acoustic signal; B: with acoustic signal), with 20 stimuli per condition. The intervals between acoustic signal and visual stimulus are set by chance. To test divided attention in the typical dual task paradigm, 100 visual and 200 acoustic stimuli are presented simultaneously. In the visual task, a specific square formed by successively appearing crosses has to be recognized, while in the acoustic task, any irregularity of continuously alternating deep and high tones has to be detected. In this test, mainly parietal and frontal structures are assessed. In flexibility, two competing stimuli (digits and letters) are presented simultaneously on the left and the right side of the screen in a series of 100 consecutive trials. The subject has to respond in an alternate way to either digit or letter as the critical stimulus by pressing a hand key on the corresponding side. This test reflects the ability to shift the focus of attention flexibly and involves frontal, parietal, and subcortical pathways. To test working memory, 100 mixed singledigits are presented consecutively on the screen. Whenever the subject identifies a digit as identical to the penultimate one, a button has to be pressed immediately. This test reflects the capacity to process and store information within a very brief period of time, to generate a short-lasting neuronal representation of a stimulus. This function is mainly attributed to frontal structures.

\section{Results and discussion}

The last cannabis use as reported by the subjects averaged $29.8 \mathrm{~h}$ (range $2 \mathrm{~h}$ to 1 week) prior to testing. Mean plasma levels of THC, THCOH, and THC$\mathrm{COOH}$ of users were low $(1.0 \pm 2.1,0.3 \pm 0.7$, and $11.4 \pm 25.0 \mathrm{ng} / \mathrm{ml}$, respectively). Mean urine levels of total THC metabolites were $321.8 \pm 1.031 \mathrm{ng} / \mathrm{ml}$ (range $0-8990 \mathrm{ng} / \mathrm{ml})$. There were high pairwise correlations among THC, THCOH, and THCCOOH levels in plasma ( $r=0.97 ; 0.91 ; 0.89$; respectively), as well as between plasma levels and total THC metabolites in urine $(r=0.90 ; 0.85 ; 0.79)$, on the one hand, and between plasma levels and the subjects' reports on the drug-free interval within $24 \mathrm{~h}$ prior to testing $(r=-0.58)$, on the other hand (all $P \mathrm{~s}=0.0001)$. These consistent results underline the credibility of the information obtained from the semistructured interview which provided the basis for estimation of the individual life dose.

In the absence of an experimental manipulation of the age of onset of cannabis use (for ethical reasons), one needs to carefully specify criteria that can support the hypothesis of an effect of early onset against alternative interpretations. The key alternative explanation is that an observed impairment is due to intoxication rather than to a persistent effect. Due to the complex pharmacokinetics of cannabinoids with accumulation in fat stores and urinary excretion of metabolites after months of abstinence (Pope et al. 1995), the question as to whether neurological impairment is due to a residue of the drug in the brain or to a distinct brain alteration effect is a serious methodological issue. How can we distinguish between these two alternative explanations? The following criteria should be fulfilled if an impairment in visual scanning is due to an early onset in cannabis use and not to acute intoxication.

1. Age of onset should be a significant predictor of the reaction times in visual scanning, but indicators of acute intoxication and cumulative toxicity should not. We measured $\mathrm{THC}+\mathrm{THCOH}$ plasma levels as indicators of acute intoxication, and estimated total life dose and present age as indicators of a potential cumulative toxic effect. A stepwise regression analysis showed that age of onset was the only significant predictor of the reaction times in visual scanning, both for the critical stimuli $\left(F=11.0, P=0.001, R^{2}=0.10\right)$ and noncritical stimuli $\left(F=11.4, P=0.001, R^{2}=0.10\right)$. All the tests reported in this paper were performed with alpha $=0.05$ and power $=0.90$. Neither $\mathrm{THC}+\mathrm{THCOH}$ plasma levels, nor estimated life dose, nor present age could predict the reaction times in visual scanning or in the other four attentional functions. Furthermore, age of onset did not predict the reaction times in any of the other four attentional functions, consistent with the hypothesis of a specific impairment. Figure 1 shows the relationship between age of onset and performance in the various attentional tasks. With early onset of cannabis use (between age 12 and 16), reaction times in visual scanning are impaired for both types of stimuli (Figs. 1A and B); when the onset is after about age 16 , no such impairment can be observed.

2. A second criterion is that the average reaction time in visual scanning should be longer in the earlyonset group than in the late-onset group, whereas the average reaction time in the late-onset group should not differ from the control group: early onset >late onset $=$ control. This prediction is implied by the 

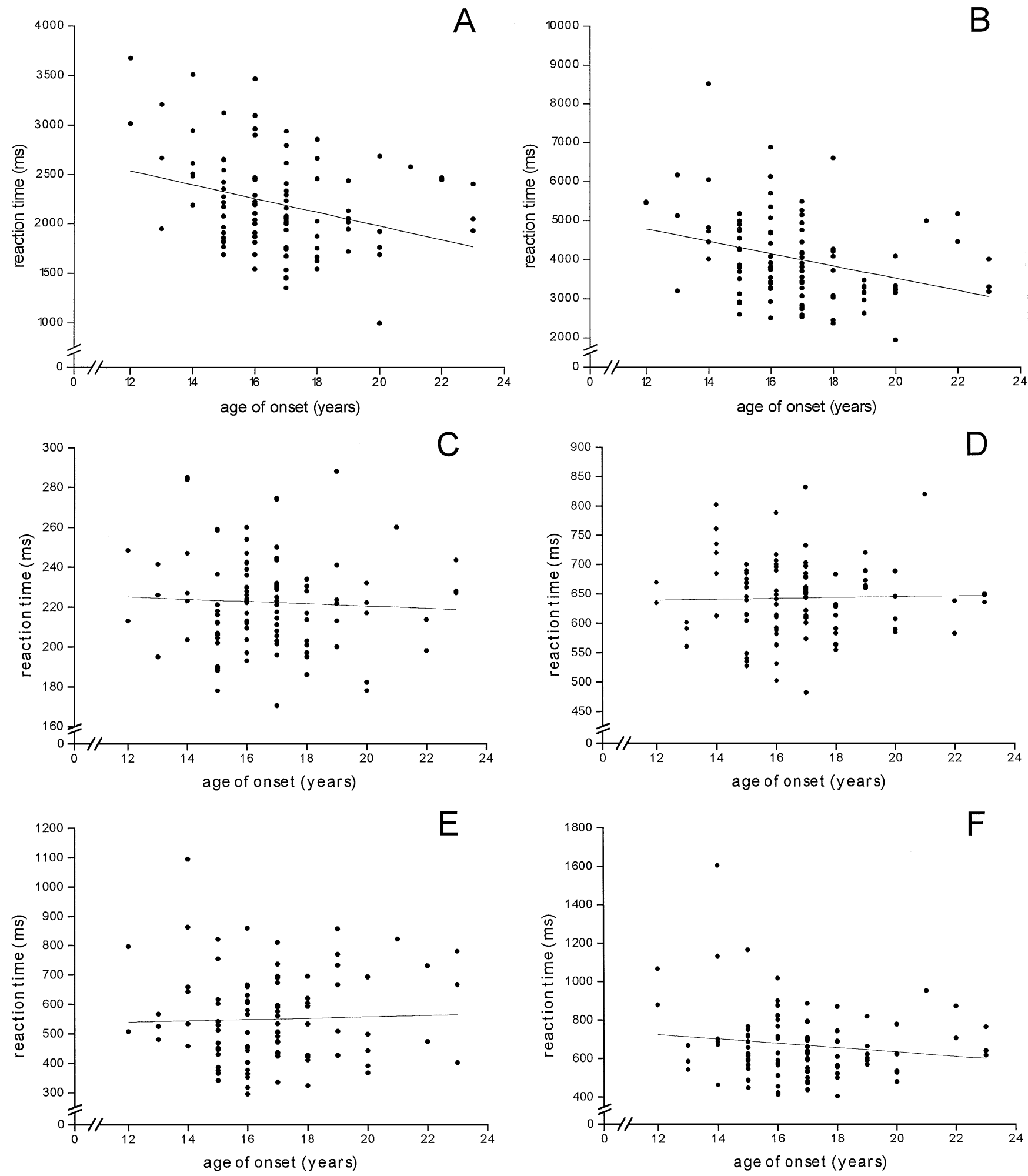

Fig. 1A-F Distribution of the medians of reaction times for visual scanning (detection of the critical stimulus: A; detection of the noncritical stimulus: B) and for alertness without tone (C) (alertness with tone shows an almost identical pattern - not shown), divided attention $(\mathbf{D})$, working memory $(\mathbf{E})$ and flexibility $(\mathbf{F})$ in relation to the age of onset of cannabis use in a fairly homogeneous population of 99 cannabis users. Beginning cannabis consumption in early adolescent years is associated with longer reaction times in visual scanning in adulthood, that is, the time of testing (cf. Table 1). An

inspection of $\mathbf{A}$ and $\mathbf{B}$ suggests that the regression line hides the effect of a vulnerable phase for cannabis use up to age 16. An increase in reaction time can mainly be observed in onset before that age, whereas no impairment is noticeable from age 17 on. The solid line represents the regression of the age of onset to the reaction time which is significant in $\mathbf{A}\left(F=11.01, P=0.001, R^{2}=0.10\right)$ and $\mathbf{B}\left(F=11.37, P=0.001, R^{2}=0.10\right)$, but not in $\mathbf{C}, \mathbf{D}, \mathbf{E}$, and $\mathbf{F}$ (all $R^{2}=0.00$ except for $\mathbf{F}$ with $R^{2}=0.02$ ). The power of these tests is. 90 for $\alpha=0.05$ 
hypothesis of a sensitive phase in which cannabis use can persistently impair visual scanning. Late onset does not lead to impairment. This prediction should hold for both types of stimuli ("critical" and "non-critical") in the visual scanning test. If, however, an observed impairment was due to acute intoxication, then the lateonset group should show the same impairment as the early-onset group, and the reaction times in both groups would be longer than in the control group: early onset $=$ late onset $>$ control. Table 1 shows the reaction times in the five attentional functions for early onset (up to age 16), late onset (17 years and older), and the control group. (The cut-off between early and late onset was chosen according to the results in Fig. 1 and is also the median of the age of onset in our users.) The two measures for visual scanning are the only ones that exhibit the pattern early onset >late onset $=$ control. There was no difference between early and late onset in any of the other attentional functions, consistent with the regression analysis reported above. Flexibility, working memory, and the various measures of alertness (except phasic alertness) showed no impairment following cannabis use, whether onset was early or late. The only other attentional functions in which cannabis users differed from controls (but not with respect to early or late onset) were phasic alertness and divided attention. Thus the effect of early onset appears to be specific for visual scanning, which is the only attentional function that displayed the pattern early onset $>$ late onset $=$ control. The fact that the reaction times in visual scanning showed this pattern is consistent with the hypothesis that the observed impairment is persistent and not just due to acute intoxication.

3. A non-experimental design can never exclude all alternative explanations, but one can try to exclude several by analyzing further data on the early-onset, lateonset, and control groups. The three groups were indistinguishable with respect to sociodemographic data and estimated premorbid intelligence (Wilson et al. 1978). They did not differ in the personality dimensions in psychometric testing. Also, the earlyonset and late-onset groups did not differ in the amount
Table 1 Effect of early versus late age of onset of regular cannabis use on five attentional functions

\begin{tabular}{|c|c|c|c|}
\hline & $\begin{array}{l}\text { Early age } \\
\text { of onset } \\
(\leq 16 \text { years) } \\
(n=48)\end{array}$ & $\begin{array}{l}\text { Late age } \\
\text { of onset } \\
(\geq 17 \text { years) } \\
(n=51)\end{array}$ & $\begin{array}{l}\text { Control group } \\
(n=49)\end{array}$ \\
\hline Age of onset & $15.0 \pm 1.1$ & $18.4 \pm 1.8$ & - \\
\hline $\begin{array}{l}\text { Attentional functions }{ }^{\mathrm{a}} \\
\text { Alertness }\end{array}$ & & & \\
\hline $\begin{array}{l}\text { Without acoustic signal } \\
\text { With acoustic signal } \\
\text { Phasic alertness } \mathrm{s}^{\mathrm{b}, \mathrm{e}}\end{array}$ & $\begin{array}{r}223.4 \pm 24.0 \\
222.7 \pm 25.2 \\
0.00 \pm 0.07\end{array}$ & $\begin{array}{r}221.3 \pm 23.7 \\
217.4 \pm 23.4 \\
0.02 \pm 0.06\end{array}$ & $\begin{array}{r}227.2 \pm 27.2 \\
214.4 \pm 26.0 \\
0.06 \pm 0.06\end{array}$ \\
\hline Divided attention $^{\mathrm{b}, \mathrm{d}, \mathrm{e}}$ & $640.0 \pm 69.2$ & $646.1 \pm 60.2$ & $588.3 \pm 64.7$ \\
\hline Flexibility & $705.4 \pm 219.1$ & $639.0 \pm 122.7$ & $657.0 \pm 191.7$ \\
\hline Working memory & $539.2 \pm 164.5$ & $560.4 \pm 142.7$ & $510.8 \pm 121.6$ \\
\hline $\begin{array}{l}\text { Visual scanning } \\
\text { Critical stimulus } \\
\text { Non-critical stimulus } \\
\text { b,c,d }\end{array}$ & $\begin{array}{l}2374.2 \pm 516.9 \\
4384.1 \pm 1178.9\end{array}$ & $\begin{array}{l}2040.9 \pm 418.3 \\
3699.7 \pm 921.2\end{array}$ & $\begin{array}{l}2132.1 \pm 496.8 \\
3626.1 \pm 995.1\end{array}$ \\
\hline $\begin{array}{l}\text { Group characteristics } \\
\text { Present age (years) } \\
\text { Male/female ratio } \\
\text { Last use before testing (h) }\end{array}$ & $\begin{array}{l}21.6 \pm 4.0 \\
28 / 20 \\
26.0 \pm 27.4\end{array}$ & $\begin{array}{l}24.8 \pm 4.3 \\
35 / 16 \\
33.4 \pm 31.2\end{array}$ & $\begin{array}{l}\quad 23.5 \pm 3.9 \\
29 / 20 \\
-\end{array}$ \\
\hline $\begin{array}{l}\text { Weekly frequency of use in the last } \\
1 / 2 \text { year (days per week) } \\
\text { Years of regular use } \\
\text { Estimated life dose (days of use) } \\
\text { THC+THCOH (ng/ml plasma) }\end{array}$ & $\begin{aligned} 3.9 & \pm 2.1 \\
4.6 & \pm 3.8 \\
1087.5 & \pm 1127.0 \\
1.9 & \pm 3.7\end{aligned}$ & $\begin{aligned} 3.2 & \pm 1.7 \\
3.9 & \pm 3.0 \\
709.8 & \pm 558.0 \\
0.7 & \pm 1.2\end{aligned}$ & $\begin{array}{l}- \\
- \\
- \\
-\end{array}$ \\
\hline
\end{tabular}

Analyses of variance were performed between the two experimental groups and the control group, and were followed by $\alpha$-error correction (Scheffé test; $\alpha=0.05$ ) for multiple testing. The differences in cannabis use habits and pharmacological analyses between the two experimental groups were analysed by $t$-test $(\alpha=0.05$; power $1-\beta=0.90)$. Mean \pm SD presented

${ }^{\mathrm{a}}$ Given are reaction times $\pm \mathrm{SD}(\mathrm{ms})$; reaction time $=$ mean of medians of reaction times

${ }^{\mathrm{b}}$ Significant group differences in the analysis of variance $(\alpha=0.05)$ between the two experimental groups (all users) and the control group

"Significant group differences between the two experimental groups "early age of onset" and "late age of onset"

dSignificant group differences between the experimental group "early age of onset" and control group eSignificant group differences between the experimental group "late age of onset" and control group 
of cannabis intake in the last 6 months, a fact which is important for excluding the alternative hypothesis that the effect of cannabis on visual scanning is due to differences in cumulative intoxication. But there are some differences between the early-onset and late-onset group (Table 1) that might be linked to the impairment of visual scanning found. The members of the early-onset group were younger (a prerequisite for the comparability of both user groups with regard to their years of regular use), there were more males, their estimated life dose was higher, and so was their THC + THCOH plasma level (Table 1). Could these differences account for the impairment of visual scanning? In order to test this possibility, a subsequent group analysis was performed, which, however, did not yield significant effects $(\alpha=0.05$, power $=0.90)$. In addition, sex, age, $\mathrm{THC}+\mathrm{THCOH}$, and estimated life dose were simultaneously used as covariates; nevertheless, the group difference in visual scanning persisted for both the critical and non-critical stimuli (all $P$ s $\leq 0.001)$. These results are again consistent with the hypothesis that there is a vulnerable phase up to about age 16, during which cannabis use permanently impairs visual scanning.

Several molecular mechanisms may explain a disintegrative input of exogenous cannabinoids during a vulnerable period of developing attention-related neuronal networks. Cannabinoids regulate gap-junction permeability, thereby controlling intercellular communication in astrocytes as well as neuron-glial interaction, for example by preventing the recruitment of subpopulations of astrocytes and the subsequent activation of contacting groups of neurons (Venance et al. 1995). In addition, regulation of a neuronal form of focal adhesion kinase by cannabinoids has been described, indicating that these compounds play a role in synaptic plasticity (Derkinderen et al. 1996).

Taken together, these results provide support for the hypothesis that early use of cannabis - up to about age 16 - is associated with a specific impairment in visual scanning in adult life. The alterations described here are subtle, and individuals seem to be largely functional. The effect of early onset is specific to visual scanning within the five attentional functions measured in this study; but this does not exclude that specific impairments may be found with other cognitive functions as well. The specificity of cannabinoid effects in turn may provide a key to understanding physiological mechanisms involved in the development of attentional functions.

\section{References}

Block, RI (1996) Does heavy marijuana use impair human cognition and brain function? JAMA 21:560-561

Braff DL, Silverton L, Saccuzzo DP, Janowsky DS (1981) Impaired speed of visual information processing in marijuana intoxication. Am J Psychiatry 138:613-617

Derkinderen P, Toutant M, Burgaya F, le Bert M, Siciliano JC, de FranciscisV, Gelman M, Girault J-A (1996) Regulation of a neuronal form of focal adhesion kinase by anandamide. Science 273:1719-1721

Fletcher JM, Page B, Francis DJ, Copeland K, Naus MJ, Davis CM, Morris R, Krauskopf D, Satz P (1996) Cognitive correlates of long-term cannabis use in Costa Rican men. Arch Gen Psychiatry 53:1051-1057

Halgren E, Marinkovic K (1995) Neurophysiological networks integrating human emotions. In: Gazzaniga MS (ed) The cognitive neurosciences. MIT, Cambridge, Mass., pp 1137-1151

Herkenham M, Lynn AB, Little MD, Johnson MR, Melvin LS, de Costa BR, Rice KC (1990) Cannabinoid receptor localization in brain. Proc Natl Acad Sci USA 87:1932-1936

Hollister LE (1986) Health aspects of cannabis. Pharmacol Rev 38: $1-20$

Kunert HJ, Derichs G, Irle E (1996) Entwicklung von Aufmerksamkeitsfunktionen im Kindesalter: Ergebnisse einer vorläufigen Normierung der computergestützten Testbatterie zur Aufmerksamkeitsprüfung (TAP) an 9- bis 12jährigen Kindern. Zeitschrift Neuropsychologie 7:92-113

Landfield PW, Cadwallader LB, Visant S (1988) Quantitative changes in hippocampal structure following long-term exposure to $\Delta^{9}$-tetrahydrocannabinol: possible mediation by glucocorticoid systems. Brain Res 443:47-62

Mailleux P, Parmentier M, Vanderhaeghen J-J (1992) Distribution of cannabinoid receptor messenger RNA in the human brain: an in situ hybridization histochemistry with oligonucleotides. Neurosci Lett 143:200-204

Matsuda LA, Lolait SJ, Brownstein MJ, Young AC, Bonner TI (1990) Structure of a cannabinoid receptor and functional expression of the cloned cDNA. Nature 346:561-564

McGlothlin WH, West LJ (1968) The marijuana problem: an overview. Am J Psychiatry 125:370-378

McLaughlin CR, Abood ME (1993) Developmental expression of cannabinoid receptor mRNA. Dev Brain Res 76:75-78

Mesulam M-M (1981) A cortical network for directed attention and unilateral neglect. Ann Neurol 10:309-325

Mesulam M-M (1990) Large-scale neurocognitive networks and distributed processing for attention, language, and memory. Ann Neurol 28:597-613

Mirsky AF (1987) Behavioral and psychophysiological markers of disordered attention. Environ Health Perspect 74: 191-199

Moeller MR, Doerr G, Warth S (1992) Simultaneous quantitation of delta-9-tetrahydrocannabinol (THC) and 11-nor-9-carboxydelta-9-tetrahydrocannabinol (THC-COOH) in serum by GC/ MS using deuterated internal standards and its application to a smoking study and forensic cases. J Forens Sci 37:969-983

Oviedo A, Glowa J, Herkenham M (1993) Chronic cannabinoid administration alters cannabinoid receptor binding in rat brain: a quantitative autoradiographic study. Brain Res 616:293-302

Pope HG, Yurgelun-Todd D (1996) The residual cognitive effects of heavy marijuana use in college students. JAMA 275:521-527

Pope HG, Gruber AJ, Yurgelun-Todd D (1995) The residual neuropsychological effects of cannabis: the current status of research. Drug Alcohol Depend 38:25-34

Posner MI, Petersen SE (1990) The attention system of human brain. Annu Rev Neurosci 13:25-42

Rodríguez de Fonseca F, Ramos JA, Bonnin A, Fernández-Ruiz JJ (1993) Presence of cannabinoid binding sites in the brain from early postnatal ages. NeuroReport 4:135-138 
Rodrígez de Fonseca F, Gorriti MA, Fernández-Ruiz JJ, Palomo T, Ramos JA (1994) Downregulation of rat brain cannabinoid binding sites after chronic $\Delta^{9}$-tetrahydrocannabinol treatment. Pharmacol Biochem Behav 47:33-40

Solowij N, Michie PT, Fox AM (1995) Differential impairments of selective attention due to frequency and duration of cannabis use. Biol Psychiatry 37:731-739

Stiglick A, Kalant H (1985) Residual effects of chronic cannabis treatment on behaviour in mature rats. Psychopharmacology $85: 346-349$

Thomas BF, Wie X, Martin BR (1992) Characterization and autoradiographic localization of the cannabinoid binding site in rat brain using $\left[{ }^{3} \mathrm{H}\right] 11-\mathrm{OH}-\Delta^{9}$-THC-DMH. J Pharmacol Exp Ther 263:1383-1390

United States Department of Health and Human Services (1996) Substance Abuse and Mental Health Services Administration Office of Applied Studies: Preliminary results from the 1996 National Household Survey on Drug Abuse, p 69

Venance L, Piomelli D, Glowinski J, Giaume C (1995) Inhibition by anandamide of gap junctions and intercellular calcium signalling in striatal astrocytes. Nature 376:590-594
Westlake TM, Howlett AC, Bonner TI, Matsuda LA, Herkenham M (1994) Cannabinoid receptor binding and messenger RNA expression in human brain: an in vitro receptor autoradiography an in situ hybridization histochemistry study of normal aged and Alzheimer's brains. Neuroscience 63:637-652

Wilson RS, Rosenbaum G, Brown G, Rourke D, Whitman D, Grisell J (1978) An index of premorbid intelligence. J Consult Clin Psychol 46:1554-1555

Zihl J, Hebel N (1997) Patterns of oculomotor scanning in patients with unilateral posterior parietal or frontal lobe damage. Neuropsychologia 35:893-906

Zimmermann P, Fimm B (1993) Diagnosis of attentional deficits: theoretical considerations and presentation of a test battery. In: Stachowiak FJ (ed) Developments in the assessment and rehabilitation of brain damaged patients. Narr Verlag, Tübingen, pp 3-30 